\title{
Innovation Momentum in A Higher Education Ecosystem (A Study at The University of Indonesia)
}

\author{
P Hutapea ${ }^{1}$, M Huseini ${ }^{2}$, R Kusumastuti ${ }^{3}$, N Thoha ${ }^{4}$ \\ ${ }_{1,2,3}$ Universitas Indonesia, Depok, Indonesia \\ ${ }^{4}$ University of Bina Nusantara, Jakarta, Indonesia
}

${ }^{1}$ parulian2010@yahoo.com

\begin{abstract}
This study aims to find a causal relationship on how the ecosystem affects individual esearchers when producing innovation in a higher education institution. It is filling the gap between existing psychological-based creativity theory and ecosystem-based organization management theory. It also answers the problem of low innovation productivity in higher education institutions by managing the innovation ecosystem. The study uses a qualitative method to find the causal relationships among variables in forming a system using causal loop diagram (CLD). It also uses a quantitative method to measure the effect of the relationships using the stock and flow diagram (SFD) of system dynamics. The post-positivism paradigm with a mixed methodology was used to explain a complex relationship among variables in the innovation ecosystem. The model was built based on theories and concepts available and supported by facts and information taken from previous unpublished research conducted by Thoha and Hutapea (2017) in 5 higher education institutions in Central Java and the hypothesis of the model will be tested and simulated at the University of Indonesia. Conflicting actions and policies to fulfill business goals and government regulation can create unfavorable conditionsfor innovation momentum. Pushing excessiveresearch and innovation targets without giving enough incentives creates a negative reaction from the researchers, fails to create a good work climate and producesa reversing effect on the productivity of innovation. Therefore management must balance their policy with emotional engagement of the researchers.
\end{abstract}

Keywords: Education, Ecosystem Affects, Innovation Ecosystem

\section{INTRODUCTION}

Research innovation is often used as an indicator to get status for developed ordeveloping countries and is also usedto gaina competitive advantage for a nation.Indonesia is one of the countries in Asia which still has a problem improving its position in research innovation. Based onthe SCI mago journal and country rank [1] Indonesiahas stayed ata low position in terms of the number of journal citations between 1996 and 2016 at number 55 as compared with Nigeria in $52^{\text {nd }}$,Malaysia in $34^{\text {th }}$, and India 9 th.

Based on the number of publications (2012-2017) out of the fourASEAN countries Indonesia has also stayed at number 4 with 54,426 publications, whereas Thailand is at 
number 3 with 81,903 publications;Singaporeis at number 2 with 119,847 publications and Malaysia is at number 1 with 164,337 publications [2].

So far the Indonesian government has spent a lot of money on research.President Joko Widodo setthe total budget for all ministries in 2019 at 24.9 trillion Rupiah [3], but he isdisappointed with the results [4].

Therefore, currently the government is still looking for ways to improve it. One way to do it is to look at the efficiency of the research innovation system, such as by studying the production process of research and innovation.

This paper studies the causal relationship among variables which contribute to research and innovation, so that it is able to show the efficiency of the system.

Research objectives:

1. To analyze a causal relationship of research and innovation variables in the HEI innovation ecosystem.

2. To analyze the creation of working conditions favorable for innovation momentum in the innovation ecosystem.

\section{THEORETICAL FRAMEWORK}

\subsection{Definition of Innovation}

Peoplesee and define innovationfrom different aspects, such as: the area coverage of innovation, the period of change affected by innovation, the impact caused by innovation and the screening process of innovation. In terms of the area of coverage, innovation can be categorized into: ideas, products, processes and behavior [5]-[8]. Based on the period of change affected by innovation there are two types of innovations: sustaining innovation and disruptive innovation [9]. Sustaining innovation is an innovation that partially and continuously happens in organizations and a disruptive innovation involves the change of overall processes, technology and business. Meanwhile, an idea can be recognized as an innovation if it has been filtered by the environment and it is ready to apply [10], [11]. According to [12], an "idea is a raw material to produce innovation".

\subsection{Sources of Innovation}

Many people try to relate innovation productiontocreativity. Reference [13] argues that creativity and innovation are often considered as different concepts, and in this case creativity can affect innovation. People with different backgrounds try to look at the source of innovation from different perspectives. Psychologists see it from an individual or personal emotions, motivation and psychological energy that affectsthe ability to innovate. In psychology creativity is related to the concept of motivation (Maslow in [14]), thriving [15], mood [16], individual listening and understanding about the environment [17], psychoanalytic creativity concept [18] and behavioral competency[19]. As a technical conceptcreativity is related to knowledge management and networking concepts [20]. Whereas, in management the concept of creativity is often related to leadership [21], [22], reward and punishment, organization climate, organization culture [23], [24] and internal or micro ecosystem [25]. Meanwhile, [18] with her psychoanalytic creativity concept argues that an individual can be creative if theyare in a space of creativity where they are able to manage their anxiety; it is influenced by internal fantasies and the outside mind is related to external realities. 


\subsection{Innovation in Organization}

Many researchers have tried to study the relationship among variables affecting innovation in organizations, but they did it partially by using different theories and concepts. Only a few writers have integrated inter-disciplinary concepts and theories of innovation; one of them is Prof Marco Iansiti from Harvard University who uses technical, management and ecosystem concepts to analyze creativity. He uses innovation theory which is based on technology as the main theory and relates it with the organizational ecosystem.

Meanwhile, a study done by tries to connect the psychological concept of innovation with management practice, but they only use two variables: security feeling and self-efficacy expectation. Both of them focus on the individual as a source of creativity and innovation. They do not explain how to derive organizational research and innovation from individual creativity and innovation.

In an organizational context the individual shares part of his schema with other group members in terms of their understanding about organizational climate and organizational context [18]. The organization climate and organization context themselves are affected by both the organization policy and the people interaction to produce creativity. Therefore the total organization creativity and innovation becomes a collection of total individual shared schemas to produce creativity and innovation. The interaction among variables to produce research innovation in the organization is supposed to be identified and scientifically tested.

\subsection{Innovation Momentum}

One way to identify the existence of innovation creation is by measuring the celebration and championing of inspiration and creativity which is called innovation momentum [16]. Organizations which are in the stage of having innovation momentum should have people who are capable to do self-creation in the organization. This condition describes a reflection of innovation success done by the researchers within the innovation ecosystem. It is also a reflection of the effectiveness of the reward and punishment system as well as innovation support [26].A literature study below identifies some variables which may contribute to the rise of innovation momentum: mood, mindset, thriving, creativity, government and organization supports. Mood and mindset comes from inside a researcher. Mood is shaped by attitude, feeling and emotion; mindset is an intellectual foundation which determines the capacity for creation [16]. 


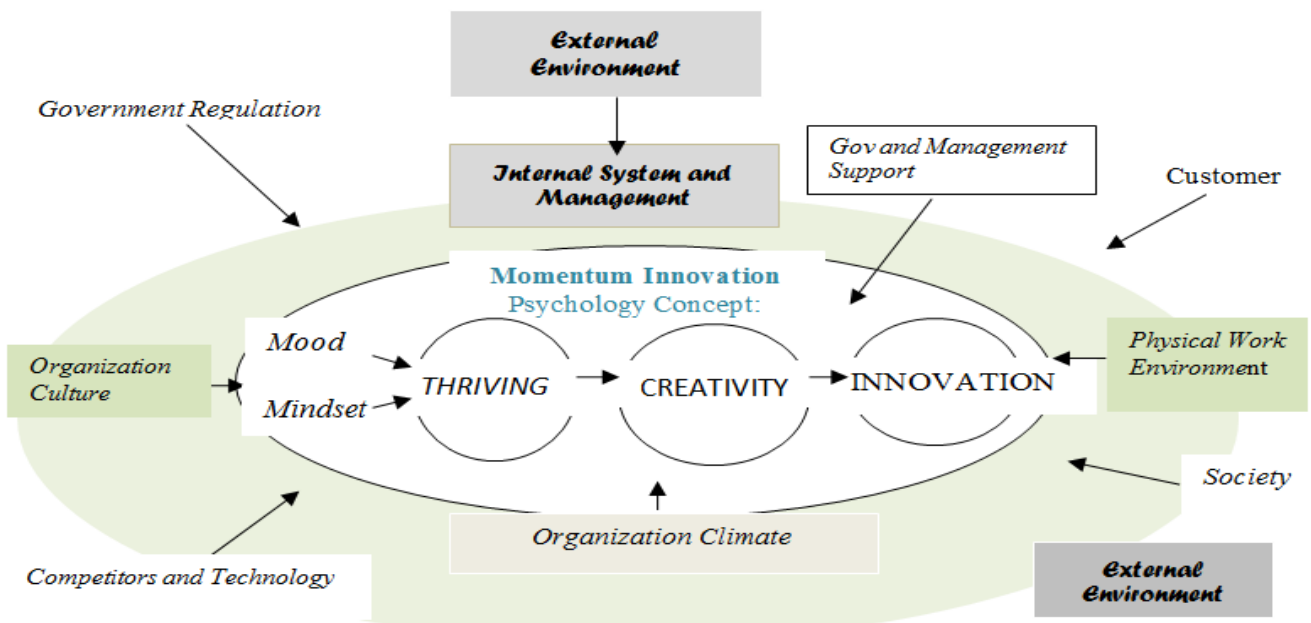

Figure 1. Innovation Momentum Model in Organization Ecosystem

Source: Rebuilt from [24], [27], [28].

By having a different mindset someone has their own inspiration and thinks differently from other people. This makes them able to change his perspective, and be willing to take a risk, finding their own interests, challenging assumptions and embracing ambiguity.

Reference [15] defines thrivingas a psychological condition where someone experiences prime vitality and a state of readiness to learn. Vitality is a positive feeling to use available energy [29]. The logical consequence of having a positive mood and mindset is it will bring creativity. Meanwhile [30] find the fact that energy level in the brains (cortical energy) affects human creativity; when someone is producing creativity the level of energy in the brain goes down and at the same time stress levels also drop.

In connection to the internal and external ecosystem, a creative person has a capacity to pay more attention to internal and external ecosystems and explore more information from there.The figure 1 describes variables that have an effect on innovation momentum.

\section{METHOD}

\subsection{Research Paradigm}

Paradigmsare beliefs and assumption that are used in the research process. It is related to the nature of reality, the connection between the researcher and the object being researched, the research value and the research process [31]. This research uses apost-positivism approach, which assumes that the reality willnotbe understood and it can only be approached (Guba in [32]). Therefore, post-positivismdepends on multiple methods to capture as much as possible realities (mixed method); for instance,an interview is needed when analyzing organization culture, because questionnaires will only capture information about organization climate (Sparrow \& Gaston in[33]). 


\subsection{The Use of System Thinking and Causal Loop Diagram (CLD)}

To find causal relationships among variables existing in the ecosystem this research uses systemthinking. The focus of the causal relationship analysis is to identify the flows coming from independent variables to dependent variables which lead to the formation of innovation momentum; this is done by using a causalloop diagram (CLD). Because interconnection in the relationships form a system [34], then the system thinking described in the causal loop relationship becomes the right tool for the qualitative analysis. Causal loop will also identify the leverage and balancing effects of variables [35], [36], [37].

\subsection{Hypothesis Building, Simulation and Stock and Flow Diagram (SFD)}

A stock and flow diagram is a collection of quantitative relationships between variables used in system dynamics. The relationship is described by an accumulation of output (stock) generated by netting the inflow and outflow created by activities. The relationship is drawn by a mathematical function which shows the amount of inflow going to the stock. Variables in SFD relate to each other with two types of feedbacks: positive (reinforcement) loops and negative (self-correction) loops.

Hypotheses in CLD and SFD model are built based on the innovation and creativity theories which are supported by facts and information taken from previous unpublished research conducted by [38]in 5 higher education institutions in Central Java. Based on the CLD model, the dynamic model using Stock Flow Diagram (SFD) is formulated to be simulated and tested at the University of Indonesia. This paper only presents the hypotheses for the simulation.

\subsection{Research Process}

The process of this research is divided into some stages as described in figure 2. It starts from conducting a literature study in which information is used for formulating a research problem, research questions and research objectives. The following step is constructing hypotheses based on research innovation theories and concepts. All relationships of the variables are analyzed in the context of system thinking and system dynamics. This will be tested and simulated by using Vensim system dynamics. The result will be processed to produce research findings and the conclusion.

\subsection{Research Strategy}

This research chooses a case study at the University of Indonesia and Prasetya Mulya University to test the hypothesis and conduct a simulation, because case studiesare very effective for illustrating phenomena in organizations [39], [40] and getting deep understanding and research context (Morris \& Wood in [41]).

\subsection{Data Collection}

To collect information for conducting a simulation and testing the hypothesis there are two types of informant will be interviewed 1. Key informants, who have formal structural positions in the organization, such as: Rector, Dean, and head of department. 2. Regular informants, consisting of team leaders, researchers and research administration staff. The total 
informants (50 persons)within HEIswill be interviewed and given the questionnaires within HEIs are 50 persons. Whereas the total number of informants from the Ministry (KemenristekDikti) is 3 persons. Besides that, focus group discussion will also be conducted.

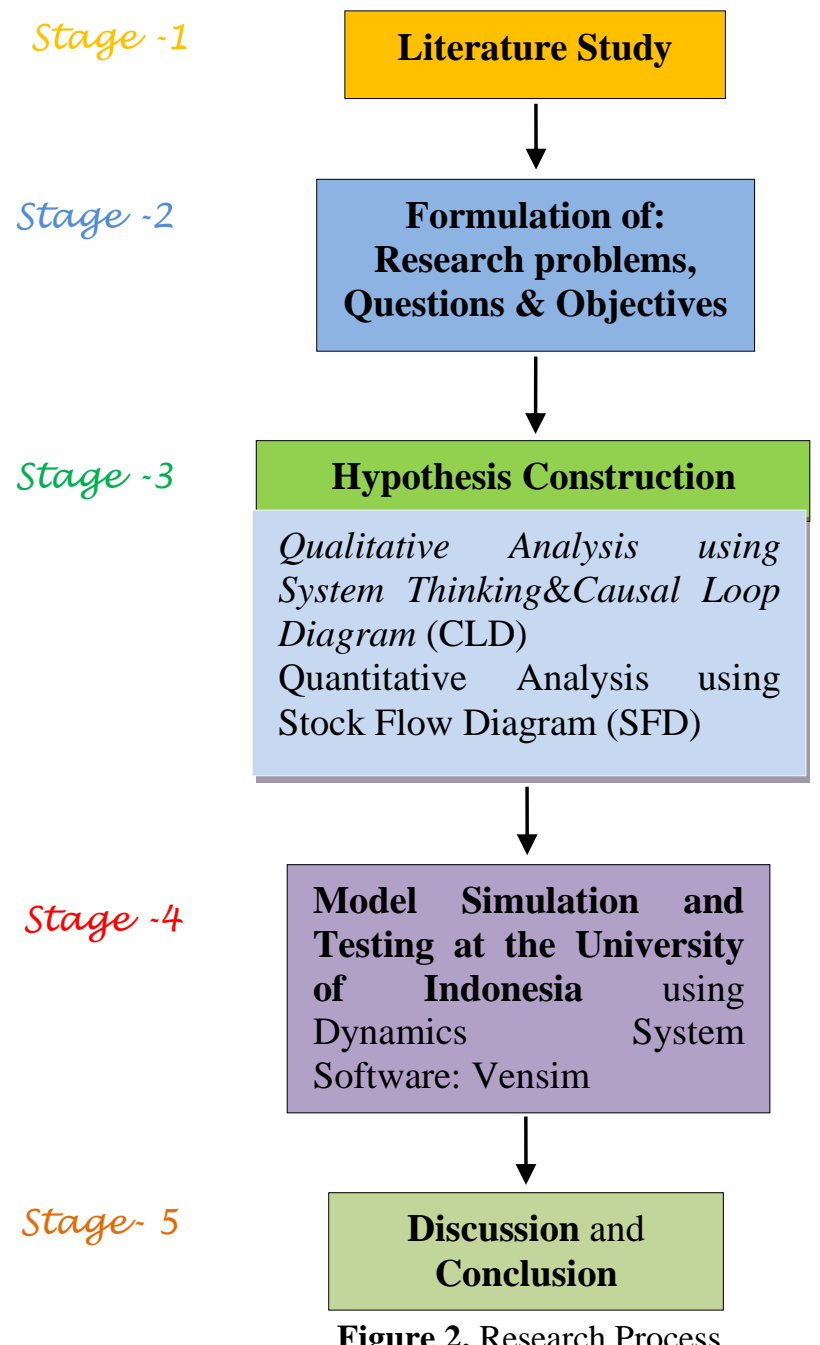

Source: Developed and Modified from [37], [42]

\section{RESULT AND DISCUSSION}

The discussion focus on the loops produced in the system thinking: production, work climate, work intensity, burn out and momentum. This result is still on progress as a part of doctorate dissertation and it will be further tested in the two HEIs. 


\subsection{Causal Loop Diagram}

Production Loop (Main loop).A productivity loop will cover the whole variables that show overallcausal relationships between variables which directly or indirectly affect research and innovation productivity. The productivity loop is constructed by some smaller loops which may haveeither positive or negative effectson productivity. The productivity loopstarts from the gap existingbetween HEI targets and its actual achievement in research and innovation. Then as a reaction to the gap some actions done by the HEIs to reduce the gap, such as increasing research and innovation budget, hiring new researchers, improving work conditions, increasing research targets and increasing work intensity (Figure 3). These actions cause reactions that come from other variables which bringan effect to the working conditions, such as teamwork, work pressure, working mood and burnout.As a result, these reactions create 4 sub-loops, such as: work climate creation, work intensity,burn-out and momentum,

Figure 3. CLD Innovation Momentum.

Sources: processed from innovation theories and supported by information and raw data from unpublished research by [38]

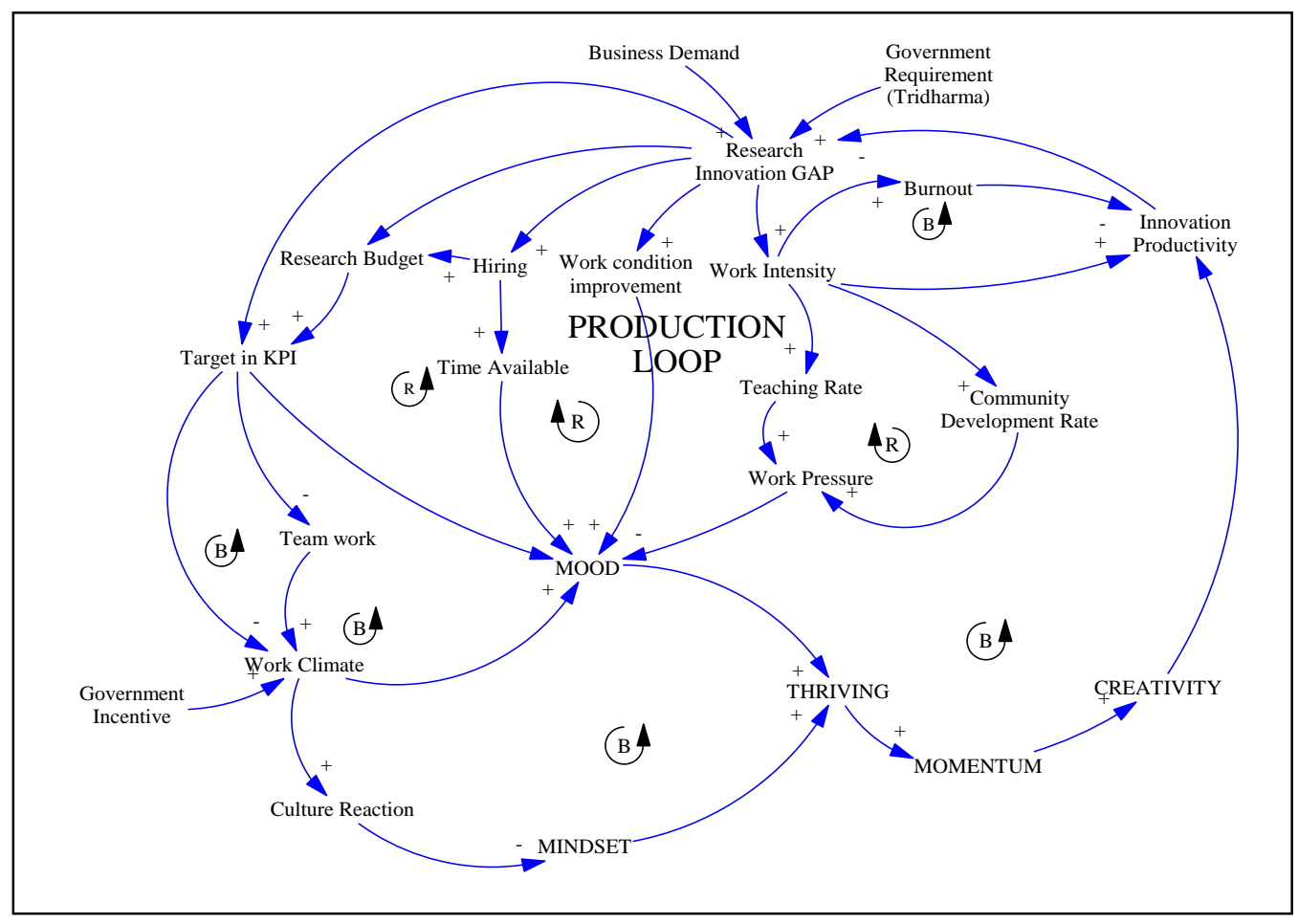

\subsubsection{Work Climate Creation (Sub Loop)}

Management policy can go in the same direction as organization culture or conflictwith it. Setting up too high research innovation targets which is not followed by giving motivating 
incentives can create a bad work climate, affect moodsand createpressure for culture change. If the culture is too strong to change then any force to change it will defect the organization fundamentals; in this case the organization needs a visionary leader to do it. Based on the information available in the field the private HEIs tend to put too high innovation targets in the KPI compared to public HEI. Some of them which also provide competitive incentives will be able to increase the productivity for innovation. But the cost of focusing too much on research innovation targets will reduce teamwork.

Work Intensity (sub loop).Excessive work load created by giving the researchers too high targets on doing research and innovation, teaching and community services (HEI Tridharma) at the same time will bring a lot of pressure, cause bad mood and lead to burn out.Since the assignment of research and innovation is given by different authorities from the assignment of teaching, then both authorities will try hardto maximize the result of the researcher's work for his (her) division. It puts a difficult position for the researchers, whose job is also as a teacher, to turn down the assignment from both superiors. This situation will put more pressure on the researcher. Once this happens it will block the momentum for creativity and gradually will reduce the productivity of research innovation. As a result, it in fact will enlarge the gap between innovation targets and innovation achievement. However, if on the contrary they are given enough time to do their research and get lot of incentives and support both from the government and the management, then it will improve their mood, thriving and productivity, which eventually will reduce the gap.Both types of HEIs give high workload to their researchers to fulfill the HEI'sTridharma (teaching, research and community services).

\subsubsection{Burn Out (Sub-Loop)}

As a consequence of the excessive work intensity burn-out will automatically arise. The limited work hours that the researchers has will make them choose overtime often, and with the limited incentive received both extrinsic or intrinsic the researchers will not easily controltheir emotions and keep motivation at a high level.

\subsubsection{Momentum (Sub-Loop)}

Reward systems can increase motivation, while good working environment can create a good ecosystem to innovate. A good working environment can come from a physical working environment and working conditions. A good physical working environment is created by providing office layout, ventilation, views and so on. Work conditionsare created by systems and procedures, rules and regulations, organization culture and climate.The resultsof those factors will make animpact on the innovation momentum. Information in the field tells us that in addition to the incentives given by the government someHEIs provide quite big incentives for published papers in Scopus journals. As it is known that Scopus journal representan acceptable reputation for publication, then the incentive given for it gives a lot of motivation for innovation. Overall, the writer presumes that a favorable condition for innovation momentum has not been achieved, because some researchers who are doing goodresearchdo not have much time for teaching and those who are good at teaching are not achieving their research targets.

\subsection{Stock Flow Diagram (SFD)}

To proof the hypothesis made in the causal relationship it has to be tested by establishing Stock and Flow Diagram (SFD), which is derived from the causal loop diagram. SFD will 
provide thearea that consists of variables that can be quantified and measured. The following figure presents SFD for innovation momentum.

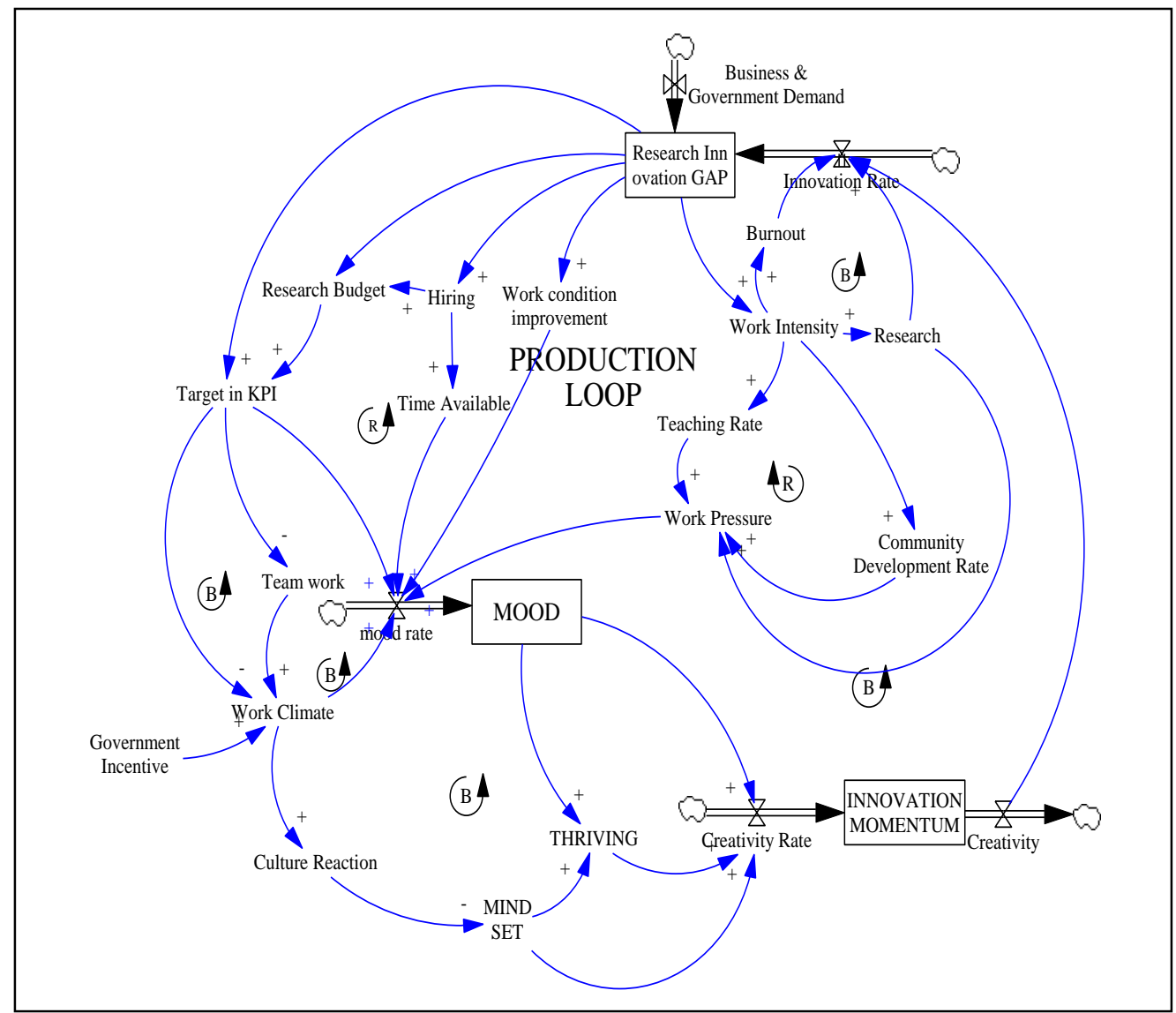

Figure 4. Stock Flow Diagram of Research Innovation

Sources: processed from innovation theories and supported by information and data from unpublished research by [38]

In Figure 4 there are some variables which are identified as stock and some as flow (rate). Innovation rate and creativity rate are the flow, where innovation momentum, mood and innovation gap are the stock. The accumulation of stock is affected by the flow which is represented by rate. The following will explain three stocks in the above diagram.

\subsubsection{Mood Stock}

The accumulation of mood is determined by the mood rate which is affected by work pressure, work condition improvement, and time available for doing research innovation field. None of those variables give enough positive effect to change the mood to the positive one. For instance, a high research innovation target in KPI will even make the mood worse if other 
work targets in connection to Tridharma are not balanced with the innovation targets. Putting more efforts in teaching activities brings more direct revenue to the institution; for some researchers it will also reduce the mood to conduct research innovation and community services.

\subsubsection{Innovation Momentum Stock}

Innovation Momentum Stock is determined by a creativity rate which is affected by thriving, mood and mindset. If the effect resultant from mood and mindset is negative then it will not bring a positive effect either to the thriving and the creativity. As a result this condition will not create innovation momentum.

\subsubsection{Research and Innovation Gap}

The reduction of research and innovation gap is determined by the innovation rate which is affected by creativity and the existence of burnout. If innovation rate does not produce enough innovation then the balancing effect caused by the burnout will take over the effect and the gap will not be reduced.

The flow and the stock variables were then tested and simulated to show the movement of the stock follow and the pattern in the hypothesis.

\section{CONCLUSION}

It is important to identify reinforcing and conflicting relationships among variables connected to research innovation in the ecosystem before establishing research innovation policy in higher education institutions. In order to be effective the policy should be able to balance the effect of individual emotion, needs, strength, and management interests.

Conflicting actions and policies to fulfill business goals and government regulation can create unfavorable conditionsfor innovation momentum. Pushing excessive research and innovation targetswithout giving enough incentives will not effectively improve research innovation productivity. Creating a good work climate and good physical conditions will stimulate individual productivity.

For future research agenda: further research should be conducted to test and simulate the dynamic of variables either directly or indirectly affecting research innovation momentum. In addition, action research is needed to produce recommendations on how HEI management should create and manage innovation momentum.

\section{REFERENCES}

[1] SCImago Journal, “Country Rank," SCImago Journal, 2016. [Online]. Available: https://www.scimagojr.com/countryrank.php.

[2] A. V Servellen, Evidence-Based Policy-Making. Universitas Indonesia: Research Intelligence, 2018.

[3] Detikfinance, "Singgung Anggaran Penelitian Rp 24 T, Jokowi: Apa Hasilnya?,” 2018. [Online]. Available: https://finance.detik.com/berita-ekonomi-bisnis/d3961968/singgung-anggaran-penelitian-rp-24-t-jokowi-apa-hasilnya.

[4] Media Indonesia, "Komersialisasi Hasil Riset Masih Sepi," Media Indonesia, 2017. [Online]. Available: http://mediaindonesia.com/read/detail/129064-komersialisasihasil-riset-masih-sepi. 
[5] R. L. Daft, “A Dual-Core Model of Organizational Innovation.,” Acad. Manag. J., vol. 21, no. 2, pp. 193-210, Jun. 1978.

[6] J. C. Sarros, B. K. Cooper, and J. C. Santora, "Building a Climate for Innovation Through Transformational Leadership and Organizational Culture," J. Leadersh. Organ. Stud., vol. 15, no. 2, pp. 145-158, Nov. 2008.

[7] R. L. Mooney, Scientific creativity: its recognition and development A conceptual model for integrating four approaches to the identification of creative talent, $\mathrm{C} \mathrm{W}$ Taylor. New York: Wiley, 1963.

[8] A. M. Obendhain, "Product and Process Innovation in Service Organization: The Influence of Organization Culture in Higher Education Institutions," J. Appl. Manag. Entrep., vol. 9, no. 3, p. 91, 2004.

[9] S. Powell, B. Olivier, and L. Yuan, "Handling disruptive innovations in HE: lessons from two contrasting case studies," Res. Learn. Technol., vol. 23, Jul. 2015.

[10] N. Anderson, K. Potočnik, and J. Zhou, "Innovation and Creativity in Organizations," J. Manage., vol. 40, no. 5, pp. 1297-1333, Jul. 2014.

[11] S. G. Scott and R. A. Bruce, "DETERMINANTS OF INNOVATIVE BEHAVIOR: A PATH MODEL OF INDIVIDUAL INNOVATION IN THE WORKPLACE," Acad. Manag. J., vol. 37, no. 3, pp. 580-607, Jun. 1994.

[12] R. Adams, J. Bessant, and R. Phelps, "Innovation management measurement: A review," Int. J. Manag. Rev., vol. 8, no. 1, pp. 21-47, Mar. 2006.

[13] D. T. Yoshida, S. Sendjaya, G. Hirst, and B. Cooper, "Does servant leadership foster creativity and innovation? A multi-level mediation study of identification and prototypicality," J. Bus. Res., vol. 67, no. 7, pp. 1395-1404, Jul. 2014.

[14] R. J. Sternberg and J. C. Kaufman, "Constraints on Creativity," in The Cambridge Handbook of Creativity, J. C. Kaufman and R. J. Sternberg, Eds. Cambridge: Cambridge University Press, 2010, pp. 467-482.

[15] G. Spreitzer, K. Sutcliffe, J. Dutton, S. Sonenshein, and A. M. Grant, "A Socially Embedded Model of Thriving at Work," Organ. Sci., vol. 16, no. 5, pp. 537-549, Oct. 2005.

[16] A. Stefanovich, Look at More. San Francisco: Jossey-Bass A Wiley Imprint, 2011.

[17] O. C. Schamer, Theory U. San Francisco, California: Berrett-Koehler Publishers, Inc, 2009.

[18] R. D. Stacey, Complexity and Creativity in Organizations. San Francisco: BerrettKoehler Publishers, 1996.

[19] L. M. Spenser and S. M. Spenser, Competence at Work. Model for Superior Performance. New York, USA: John Wiley \& Sons, Inc, 1993.

[20] M. A. Schilling and C. C. Phelps, "Interfirm Collaboration Networks: The Impact of Large-Scale Network Structure on Firm Innovation," Manage. Sci., vol. 53, no. 7, pp. 1113-1126, Jul. 2007.

[21] B. S. Pawar and K. K. Eastman, "The Nature and Implications of Contextual Influences on Transformational Leadership: A Conceptual Examination," Acad. Manag. Rev., vol. 22, no. 1, pp. 80-109, Jan. 1997.

[22] H. Hu, Q. Gu, and J. Chen, "How and when does transformational leadership affect organizational creativity and innovation?," Nankai Bus. Rev. Int., vol. 4, no. 2, pp. 147-166, 2013.

[23] E. Schein, Organizational Culture and Leadership. Jossey-Bass: A Wiley Imprint, 2004.

[24] D. B. F. Trias and P. Kotler, The A-to-F Model Winning at Innovation. New York: 
Palgrave Macmillian, 2015.

[25] J. N. Choi, "Change-oriented organizational citizenship behavior: effects of work environment characteristics and intervening psychological processes," J. Organ. Behav., vol. 28, no. 4, pp. 467-484, May 2007.

[26] H.-C. Hsiao, J.-C. Chang, and S.-C. Chen, "The Influence of Support for Innovation on Organizational Innovation: Taking Organizational Learning as a Mediator," AsiaPacific Educ. Res., vol. 23, no. 3, pp. 463-472, 2013.

[27] W. Wang and Y. Wang, "Integrated Innovation Theory: Theory Exploration of a Complex System," Manag. Eng., no. 23, pp. 228-236, 2016.

[28] J. C. Wallace, M. M. Butts, P. D. Johnson, F. G. Stevens, and M. B. Smith, "A Multilevel Model of Employee Innovation,” J. Manage., vol. 42, no. 4, pp. 982-1004, 2013.

[29] G. A. Nix, R. M. Ryan, J. B. Manly, and E. L. Deci, "Revitalization through SelfRegulation: The Effects of Autonomous and Controlled Motivation on Happiness and Vitality," J. Exp. Soc. Psychol., vol. 35, no. 3, pp. 266-284, 1999.

[30] C. Martindale and J. Armstrong, "The Relationship of Creativity to Cortical Activation and its Operant Control,” J. Genet. Psychol., vol. 124, no. 2, pp. 311-320, Jun. 1974.

[31] C. C. Lilly, "Book Review: Creswell, John. (1997). Qualitative inquiry and research design: Choosing among five traditions.," Networks An Online J. Teach. Res., vol. 1, no. 1, p. 62, Jan. 1998.

[32] N. K. Denzin and Y. S. Lincoln, "Discipline and Practice of Qualitative Research," in Handbook of Qualitative Research, Thousand Oaks: Sage, 2000.

[33] P. Agarwal, "The Moderating Effect of Strength of Organizational Climate on the Organizational Outcomes," J. Indian Acad. Appl. Psychol., vol. 41, no. 4, pp. 71-76, 2015.

[34] S. Hardjosoekarto, "Berfikir Serba Sistem (System Thinking) dan Komponen Terkait. Lecture Material."

[35] J. D. Sterman, "Systems dynamics modeling: tools for learning in a complex world," IEEE Eng. Manag. Rev., vol. 30, no. 1, pp. 42-42, 2002.

[36] P. Checkland, Systems Thinking, Systems Practice. West Sussex, England: John Wiley \& Sons, Ltd., 1999.

[37] E. K. Maani and Y. Cavana, System Thinking Modelling. New Zealand: Pearson Education, 2000.

[38] N. Thoha and P. Hutapea, The Identification of Elements Affecting Research and Innovation in Higher Education: A Study of Organizational Effectiveness using the $7 S$ McKinsey Framework in Higher Education Institutions. Jakarta: Unpublished research Binus University, 2017.

[39] R. K. Yin, Case Study Research: Design and Methods. USA: SAGE Publications, 2013.

[40] J. W. Creswell and C. N. Poth, Qualitative Inquiry \& Research DesignChoosing Among Five Approaches, 4th ed. USA: SAGE Publications Inc., 2018.

[41] M. Saunders, P. Lewis, and A. Thornhill, A Research Methods for Business Students. England: Pearson Education Limited, 2016.

[42] A. Palomba, "Professional Norms and Race in the North American Video Game Industry," Am. Commun. J., vol. 18, no. 1, pp. 63-82, 2016. 